DOI

\title{
ХАРАКТЕРИСТИКА ВЕГЕТАТИВНОГО СТАТУСА ПОДРОСТКОВ С ГОЛОВНОЙ БОЛЬЮ НАПРЯЖЕНИЯ
}

\section{○К. А. Степанченко \\ Харьковская медицинская академия последипломного образования}

РЕЗЮМЕ. Изучено состояние вегетативной нервной системы у подростков с головной болью напряжения. Установлено, что у подростков с головной болью напряжения присутствуют симптомы вегетативной дисфункции (90 \%) с признаками вегетативной дисрегуляции респираторной и кардиоваскулярной систем. Клинические нарушения вегетативного статуса указывают на недостаточную активацию парасимпатического отдела с относительным преобладанием симпатического тонуса, а также на нарушение вегетативной регуляции при нагрузочных пробах, что проявляется недостаточной и парадоксальной вегетативной активностью (чрезмерностью и недостаточностью) вегетативного обеспечения физической деятельности. Эти изменения учащаются с учащением болевых цефалгических эпизодов.

КЛЮЧЕВЫЕ СЛОВА: головная боль напряжения, подростки, вегетативная нервная система.

Введение. По литературным данным, у пациентов, страдающих головной болью напряжения (ГБН), достоверно чаще, чем в популяции, выявляется синдром вегетативной дистонии, причем наиболее ярко у детей $[1,2]$. Взаимосвязь ГБН, синдрома вегетативной дистонии и диссомнических расстройств может являться свидетельством общности их патогенеза и роли дисфункции лимбикоретикулярного комплекса в их развитии. В литературе нет единого мнения по поводу превалирования ваго- или симпатикотонии в вегетативном гомеостазе у больных с ГБН $[3,4]$. Несмотря на то, что ГБН у подростков считается индикатором наличия психовегетативных расстройств, вегетативные нарушения при этой форме цефалгии, а также их роль в формировании ГБН в подростковом возрасте изучены недостаточно, что не позволяет грамотно планировать и проводить дифференцированные лечебно-профилактические мероприятия [5].

Цель исследования: изучить роль вегетативных нарушений в формировании ГБН у подростков.

Материал и методы исследования. За период с 2005 по 2015 год проведены клинические наблюдения и специальные функциональные исследования 320 подростков в возрасте от 13 до 18 лет (184 (57,5\%) девочки и 136 (42,5\%) мальчиков), страдающих ГБН. Средний возраст девочек составлял $15,8 \pm 1,2$ года, мальчиков $16,1 \pm 1,3$ года. Группой контроля служили 50 клинически здоровых подростков (22 мальчика и 28 девочек). Все подростки, участвовавшие в обследовании, являлись учениками общеобразовательных школ г. Харькова. Диагностика ГБН проводилась в соответствии с критериями классификации Международного общества по изучению ГБ (IHS - 2003) [6]. Из общей группы подростков с ГБН выделено 3 группы с разными формами
ГБН: I группа - нечастая эпизодическая головная боль напряжения (НЭГБН) - 141 чел.; II группа частая эпизодическая головная боль напряжения (ЧЭГБН) - 123 чел.; III группа - хроническая головная боль напряжения (ХГБН) - 56 чел.

Исследование вегетативной нервной системы (ВНC):

а) для выявления вегетативной дистонии и степени ее выраженности (в баллах) проводилось анкетирование с использованием скрининганкеты (Вейн А. М., 1998);

6) определение вегетативного тонуса в сердечнососудистой системе с вычислением вегетативного индекса Кердо (ВИ);

в) изучение вегетативной реактивности с использованием глазо-сердечной пробы Ашнера;

г) исследование вегетативного обеспечения физической деятельности в ортоклиностатической пробе.

Статистическая обработка проведена общепринятыми методами с вычислением процентов, средних значений и их ошибок с использованием компьютерных программ «Statgraphics 5.0, Plus», Microsoft Excel 2007. При оценке достоверности различий выборок использовали t-критерий Стьюдента, критерий U Вилкоксона-Манна-Уитни, Т (парный критерий Вилкоксона), метод углового преобразования Фишера.

Результаты и обсуждение. Изучение вегетативных нарушений по специализированному опроснику выявило ту или иную степень вегетативной дисфункции у подавляющего большинства пациентов с ГБН (90,9 \%), что существенно превышало показатели у подростков контрольной группы - 9,1 \% (табл. 1). Причем выраженные вегетативные нарушения (>30 баллов) наблюдались у 128 (40 \%) подростков с ГБН и только у 1 школьника (2 \%) в контроле. Эти данные подтверждает и сравнительный анализ среднего балла вегетативного 
Огляди літератури, оригінальні дослідження, погляд на проблему

опросника: у подростков с ГБН - $(37,09 \pm 10,87) ;$ у их здоровых сверстников - $(12,1 \pm 7,9)(p<0,001)$. Необ-

был выше $(39,1 \pm 4,4)$, чем у мальчиков $(27,2 \pm 11,5)$ ходимо отметить, что у девочек с ГБН средний балл

$(p<0,05)$. Количество баллов с достоверностью нарастало $(p<0,05)$ при учащении эпизодов ГБН.

Таблица 1. Характеристика вегетативных нарушений у больных с головной болью напряжения

\begin{tabular}{|c|c|c|c|c|c|c|c|c|}
\hline \multirow[t]{2}{*}{ Синдром вегетативной дисфункции } & \multicolumn{2}{|c|}{ НЭГБН (n=141) } & \multicolumn{2}{|c|}{ ЧЭГБН (n=123) } & \multicolumn{2}{|c|}{ ХГБН $(n=56)$} & \multicolumn{2}{|c|}{$\begin{array}{l}\text { Контрольная } \\
\text { группа }(n=50)\end{array}$} \\
\hline & abc. & $\%$ & abc. & $\%$ & a6c. & $\%$ & a6c. & $\%$ \\
\hline $\begin{array}{l}\text { Отсутствие СВД (<15 баллов по вопроснику } \\
\text { вегетативных нарушений) }\end{array}$ & 28 & $19,9 * *$ & 17 & $13,8 * *$ m & 0 & $0 * * \diamond \diamond$ & 40 & 80 \\
\hline $\begin{array}{l}\text { Наличие СВД (>15 баллов по вопроснику } \\
\text { вегетативных нарушений) }\end{array}$ & 92 & $65,2 * * \bullet \bullet$ & 39 & $31,7^{*}$ & 16 & $28,6 \diamond \diamond$ & 9 & 18 \\
\hline $\begin{array}{l}\text { Выраженные вегетативные нарушения } \\
\text { (>30 баллов) }\end{array}$ & 21 & $14,9 * * \bullet \bullet$ & 67 & $54,5 * *$ & 40 & $71,4 * * \diamond \diamond$ & 1 & 2 \\
\hline
\end{tabular}

Примечание. Достоверность различий по методу углового преобразования Фишера: * - p $<0,05 ; * *-p<0,01 ; * * *-p<0,001$ в сравнении с контрольной группой; $\bullet-p<0,05 ; \bullet \bullet-p<0,01 ; \bullet \bullet-p<0,001$ при сопоставлении показателей больных с НЭГБН и ЧЭГБН; $\diamond-p<0,05 ; \diamond \diamond-p<0,01 ; \diamond \diamond \diamond-p<0,001$ при сопоставлении показателей больных с НЭГБН и ХГБН; $-p<0,05 ; \boldsymbol{\bullet -}-p<0,01$; -1. - p < 0,001 при сопоставлении показателей больных с ЧЭГБН и ХГБН.

Представленные в таблице 2 данные свидетельствуют, что среди подростков, страдающих ГБН, с наибольшей частотой встречались респираторные проявления вегетативной дисфункции, признаки вегетативной дисрегуляции кардиоваскулярной системы. Реже отмечались гастроинтестинальные симптомы и наличие обмороков. Нарушение функции ЖКТ, ощущение сердцебиения, "замирания", "остановки сердца», затруднения при дыхании достоверно чаще регистрировалось в группе подростков с ХГБН.

Таблица 2. Представленность симптомов вегетативной дисфункции в группах обследования (\%)

\begin{tabular}{|l|l|l|l|l|}
\hline \multicolumn{1}{|c|}{ Симптомы } & \multicolumn{1}{|c|}{$\begin{array}{c}\text { НЭГБН } \\
(\mathrm{n}=141)\end{array}$} & \multicolumn{1}{|c|}{$\begin{array}{c}\text { ЧЭГБН } \\
(\mathrm{n}=123)\end{array}$} & ХГБН (n=56) & $\begin{array}{l}\text { Контрольная } \\
\text { группа }(\mathrm{n}=50)\end{array}$ \\
\hline Изменение окраски кожи лица & $31,9^{* *}$ & $30,1^{* *}$ & $28,6^{* *}$ & 4 \\
\hline Похолодание кистей и стоп & $53,9^{* *}$ & $50,4^{* *}$ & $51,8^{* *}$ & 6 \\
\hline Изменение окраски кистей и стоп & $26,2^{* *}$ & $22,8^{* *}$ & $21,4^{* *}$ & 4 \\
\hline Повышенная потливость & $34,8^{* *}$ & $29,3^{* *}$ & $30,4^{* *}$ & 10 \\
\hline $\begin{array}{l}\text { Ощущение сердцебиения, «замирания», «остановки } \\
\text { сердца» }\end{array}$ & $24,8^{* *} \bullet$ & $30,1^{* *}$ & $30,4^{* * \diamond}$ & 6 \\
\hline Затруднения при дыхании & $34 * * \bullet$ & $55,3^{* *}$ & $64,3^{* * \diamond \diamond}$ & 2 \\
\hline Нарушения функции желудочно-кишечного тракта & $17,7^{*}$ & $20,3^{* *}$ & $23,2^{* * \diamond}$ & 6 \\
\hline Наличие обмороков & $17,7^{*}$ & $17,9^{* *}$ & $14,3^{* *}$ & 2 \\
\hline Быстрая утомляемость & $29,1^{* *}$ & $30,1^{* *}$ & $32,1^{* *}$ & 12 \\
\hline
\end{tabular}

Примечание. Достоверность различий по методу углового преобразования Фишера: * $-p<0,05 ; * *-p<0,01 ; * * *-p<0,001$ в сравнении с контрольной группой; $\bullet-p<0,05 ; \bullet \bullet-p<0,01 ; \bullet \bullet-p<0,001$ при сопоставлении показателей больных с НЭГБН и чЭГБН; $\diamond-p<0,05 ; \diamond \diamond-p<0,01 ; \diamond \diamond \diamond-p<0,001$ при сопоставлении показателей больных с НЭГБН и ХГБН; $\mathbf{- p}<0,05 ; \boldsymbol{\square}-\mathrm{p}<0,01$; m- $\mathbf{m}<0,001$ при сопоставлении показателей больных с ЧЭГБН и ХГБН.

По показателям вегетативного тонуса в сердечно-сосудистой системе больные с ГБН достоверно отличались от здоровых исходной симпатической активацией (табл. 3). Средние величины чСС, АДс и ВИ были выше, чем в контроле, что указывало на недостаточную активацию парасимпатического отдела ВНС и относительное преобладание симпатического тонуса в кардиоваскулярной системе. В контрольной группе и группе больных с НЭГБН отмечены достоверно более низкие величины ВИ $(+2,6 \pm 0,6$ и +4,4 11,4 соответственно), чем у больных с ЧЭГБН и ХГБН $(+7,7 \pm 2,8$ и $+10,2 \pm 3,7$ соответственно) $(p<0,05)$.

Исследование вегетативной реактивности выявило у больных с ГБН меньшее, чем в контроле, снижение ЧСС от фона, что свидетельствовало о снижении вегетативной реактивности и, повидимому, было обусловлено недостаточной ак- 
Огляди літератури, оригінальні дослідження, погляд на проблему

тивацией парасимпатического отдела ВНС на фоне симпатикотонии. У пациентов с ХГБН достоверно чаще, по сравнению с группой контроля, отмеча- лась извращённая вегетативная реактивность, что могло указывать на гиперактивацию симпатической нервной системы у данной группы подростков.

Таблица 3. Показатели вегетативного тонуса, реактивности в группах обследованных (\%)

\begin{tabular}{|c|c|c|c|c|c|c|c|c|}
\hline \multirow[t]{2}{*}{ Признак } & \multicolumn{2}{|c|}{ НЭГБН (n=141) } & \multicolumn{2}{|c|}{ ЧЭГБН (n=123) } & \multicolumn{2}{|c|}{ ХГБН (n=56) } & \multicolumn{2}{|c|}{$\begin{array}{l}\text { Контрольная } \\
\text { группа }(n=50)\end{array}$} \\
\hline & a6c. & $\%$ & a6c. & $\%$ & a6c. & $\%$ & a6c. & $\%$ \\
\hline $\begin{array}{l}\text { Вегетативный тонус } \\
\text { нормотония }\end{array}$ & 18 & $12,8 \bullet \bullet$ & 1 & $0,8 * *$ & 0 & $0 * * \diamond \diamond$ & 8 & 16 \\
\hline симпатикотония & 88 & $62,4^{*}$ & 86 & $69,9 * *$ m & 47 & $83,9 * * \diamond \diamond$ & 23 & 46 \\
\hline парасимпатикотония & 35 & $24,8 *$ & 36 & $29,3 \mathbf{m}$ & 9 & 16,1 ** & 19 & 38 \\
\hline $\begin{array}{l}\text { Вегетативная реактивность } \\
\text { нормальная }\end{array}$ & 20 & $14,2^{* *} \bullet \bullet$ & 5 & $4,1 * *$ & 3 & $5,4 * * \diamond$ & 23 & 46 \\
\hline недостаточная & 86 & $61,0 * * \bullet \bullet$ & 96 & 78,0 ** & 41 & $73,2 * * \diamond$ & 13 & 26 \\
\hline избыточная & 17 & $12,1^{*}$ & 14 & $11,4^{*}$ & 5 & $8,9 *$ & 12 & 24 \\
\hline извращённая & 10 & $7,1^{*}$ & 9 & 7,3 & 8 & $14,3^{*}$ & 2 & 4 \\
\hline
\end{tabular}

Примечание. Достоверность различий по методу углового преобразования Фишера: * $-\mathrm{p}<0,05 ; * *-p<0,01 ; * * *-p<0,001$ в сравнении с контрольной группой; $\bullet-p<0,05 ; \bullet-p<0,01 ; \bullet \bullet-p<0,001$ при сопоставлении показателей больных с НЭГБН и ЧЭГБН; $\diamond-\mathrm{p}<0,05 ; \diamond \diamond-\mathrm{p}<0,01 ; \diamond \diamond \diamond-\mathrm{p}<0,001$ при сопоставлении показателей больных с НЭГБН и ХГБН; $\mathbf{\bullet}-\mathrm{p}<0,05 ; \boldsymbol{m}-\mathrm{p}<0,01$; m- - < 0,001 при сопоставлении показателей больных с ЧЭГБН и ХГБН.

При исследовании вегетативного обеспечения физической деятельности отмечены повышенный прирост ЧСС в ортостатической пробе у больных с НЭГБН на 3-й мин и у подростков с ЧЭГБН - на 1-й мин по сравнению с контрольной группой, что могло указывать на избыточность вегетативного обеспечения деятельности, возможно, за счёт повышенных симпатических реакций у данных групп пациентов (табл. 4).
У больных с ХГБН, по сравнению со здоровыми сверстниками, на 1-й, 3-й и 5-й минутах прирост ЧСС в ортостатической пробе был меньше, также отмечалось меньшее снижение ЧСС от фона в клиностатической пробе, что могло указывать на нарушение адаптивной деятельности ВНС и на явления энергодефицита у подростков с выраженной дисфункцией неспецифических систем мозга.

Таблица 4. Показатели вегетативного обеспечения физической деятельности в группах обследованных

\begin{tabular}{|c|c|c|c|c|}
\hline Показатели & НЭГБН (n=141) & ЧЭГБН (n=123) & ХГБН $(n=56)$ & $\begin{array}{l}\text { Контрольная } \\
\text { группа }(n=50)\end{array}$ \\
\hline \multicolumn{5}{|c|}{$\begin{array}{c}\text { Вегетативное обеспечение } \\
\text { Ортостатическая проба, уд/мин }\end{array}$} \\
\hline Фон & $71,1 \pm 5,3$ & $71,4 \pm 6,2$ & $74,4 \pm 6,4$ & $69,7 \pm 5,4$ \\
\hline Сдвиг ЧСС 1 мин & $+17,3 \pm 2,9 \bullet$ & $+21,1 \pm 1,2 * m$ & $+14,6 \pm 1,6 * \diamond$ & $+16,4 \pm 1,5$ \\
\hline Сдвиг ЧСС 3 мин & $+22,2 \pm 1,5^{*}$ & $+18,1 \pm 0,9$ ш & $+15,9 \pm 1,4 * \diamond$ & $+19,1 \pm 1,1$ \\
\hline Сдвиг ЧСС 5 мин & $+18,8 \pm 1,3$ & $+18,3 \pm 1,2$ ш & $+13,6 \pm 1,2 * \diamond$ & $+18,6 \pm 1,2$ \\
\hline \multicolumn{5}{|c|}{ Клиностатическая проба, уд/мин } \\
\hline Фон & $70,5 \pm 4,4$ & $71,4 \pm 5,4$ & $73,4 \pm 5,3$ & $67,1 \pm 5,3$ \\
\hline Сдвиг ЧСС 1 мин & $-11,1 \pm 0,6$ & $-10,5 \pm 1,5$ & $-10,8 \pm 1,5^{*}$ & $-12,2 \pm 1,0$ \\
\hline Сдвиг ЧСС 3 мин & $-14,3 \pm 0,8$ & $-13,3 \pm 0,9$ & $-12,5 \pm 1,2^{*}$ & $-14,2 \pm 1,1$ \\
\hline Сдвиг ЧСС 5 мин & $-13,1 \pm 0,7$ & $-13,2 \pm 1,0$ & $-12,2 \pm 1,1$ & $-13,1 \pm 1,2$ \\
\hline
\end{tabular}

Примечание. Достоверность различий по критерию U Вилкоксона-Манна-Уитни: * - p<0,05; ** - p<0,01; *** - p $<0,001$ в сравнении с контрольной группой; •-p $<0,05 ; \bullet \bullet-p<0,01 ; \bullet \bullet \bullet-p<0,001$ при сопоставлении показателей больных с НЭГБН и ЧЭГБН; $\diamond-\mathrm{p}<0,05 ; \diamond \diamond-\mathrm{p}<0,01 ; \diamond \diamond \diamond-\mathrm{p}<0,001$ при сопоставлении показателей больных с НЭГБН и ХГБН; $\mathbf{\bullet}-\mathrm{p}<0,05 ; \boldsymbol{m}-\mathrm{p}<0,01$; - -

Выводы. Для подростков с головной болью напряжения характерно наличие симптомов вегетативной дисфункции $(90,9 \%)$ с признаками вегетативной дисрегуляции респираторной и кар- диоваскулярной систем. Клинические нарушения в вегетативном статусе указывают на недостаточную активацию парасимпатического отдела вегетативной нервной системы с относительным 
Огляди літератури, оригінальні дослідження, погляд на проблему

преобладанием симпатического тонуса, а также нарушения вегетативного регулирования при нагрузочных пробах, проявляющееся недостаточной и парадоксальной вегетативной реактивностью и нарушением (избыточностью и недостаточностью) вегетативного обеспечения физической деятельности. Эти изменения становятся более выраженными с учащением болевых цефалгических эпизодов.

Перспективы дальнейших исследований. Возникает необходимость в разработке лечебно-профилактических мероприятий с учетом изменений в вегетативном статусе подростков с головной болью напряжения.

\section{ЛИТЕРАТУРА}

1. Маневич Т. М. Хронические головные боли напряжения у детей и подростков: клиническая и психологическая оценка / Т. М. Маневич, Н. Н. Яхно, Е. Д. Соколова // Журнал неврол. и псих. им. С. С. Корсакова. 2004. - №2. - C. 4-7.

2. Casucci G. Headache in school age. / G. Casucci, R. Terlizzi, S. Cevoli // Neurol Sci. -2014. - Vol. 35, Suppl 1. P. 31-36.

3. Gass J. J. Autonomic dysregulation in headache patients. / J. J. Gass, A. G. Glaros // Appl. Psychophysiol. Biofeedback. - 2013. - Vol. 38(4). - P. 257-263.
4. Болевые синдромы в неврологической практике / Вейн А. М., Вознесенская Т. Г., Данилов А Б. [и др.] М. : МЕДпресс-информ, 2001. - 368 с.

5. Primary headache in children and adolescents - diagnosis and treatment / A. K. Matar, N. C. Kerem, I. Srugo, J. Genizi // Harefuah. - 2015. - Vol. 154 (12). - P. 795-803.

6. Headache Classification Committee of International Headache Society: International Classification of Headache Disorders 3rd Edition (beta version) // Cephalalgia. 2013. - Vol. 33 (9). - P. 659-664.

\section{CHARACTERISTICS OF THE VEGETATIVE STATUS OF ADOLESCENTS WITH TENSION-TYPE HEADACHE}

\section{Kharkiv Medical Academy of Postgraduate Education}

\section{@K. A. Stepanchenko}

SUMMARY. The state of the autonomic nervous system in adolescents with tension-type headache was examined. Adolescents with tension-type headache had symptoms of autonomic dysfunction ( $90.9 \%)$ with signs of autonomic dysregulation of the respiratory and cardiovascular system; inadequate activation of the parasympathetic part of the autonomic nervous system, relative predominance of sympathetic tone, dysfunction of the vegetative regulation during stress testing (insufficient and paradoxical autonomic reactivity; redundancy and insufficiency of vegetative support of physical activity). These changes become more pronounced with increasing frequency of painful episodes.

KEY WORDS: tension-type headache, adolescents, the autonomic nervous system. 